\title{
Incorporation of Aza-Glycine into Collagen Peptides
}

\author{
Samuel D. Melton, Mason S. Smith, and David M. Chenoweth* \\ Department of Chemistry, University of Pennsylvania, 231 South 34th Street, \\ Philadelphia, Pennsylvania 19104-6323, United States
}

Table of Contents

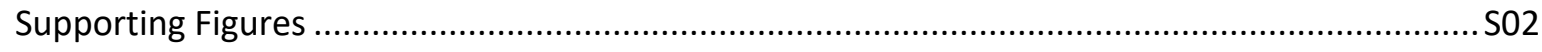

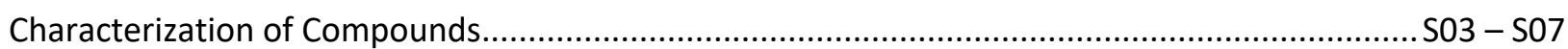

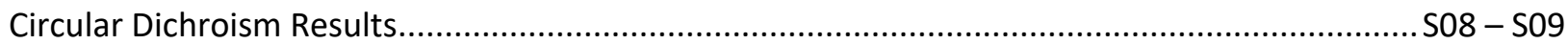




\section{SUPPORTING FIGURES}

Table S1. Comparison of azGly Coupling Efficiency onto Different Terminal Residues

$\begin{gathered}\text { terminal residue prior to } \\ \text { azGly coupling }\end{gathered}$
Aspoline
Asparagine

Table S1. For all reactions, 10 equiv. of Fmoc-hydrazine and 10 equiv. of coupling reagent were used. The couplings were performed at $60^{\circ} \mathrm{C}$ in NMP for 15 minutes. Double couplings were performed in all cases. Coupling efficiency is reported as determined by analytical HPLC after cleavage of the peptide from resin. 
HPLC CHROMATOGRAMS OF COMPOUNDS

1: Fmoc-(azG)-(POG) ${ }_{4}-\mathrm{NH}_{2}$

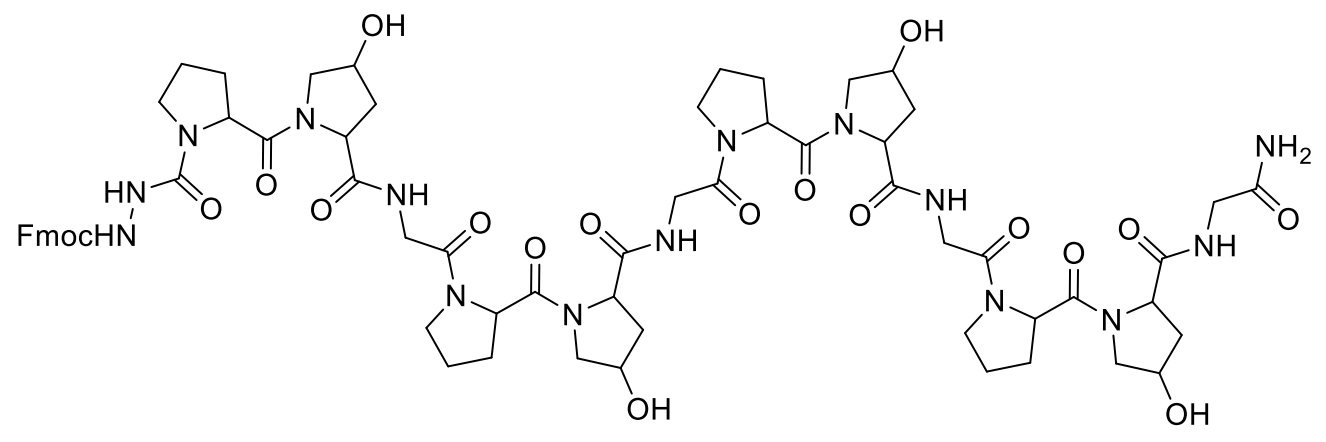

Pure HPLC Chromatogram: $5-50 \% \mathrm{CH}_{3} \mathrm{CN}$ in $0.1 \%$ TFA $\mathrm{H}_{2} \mathrm{O}$ over 30 min

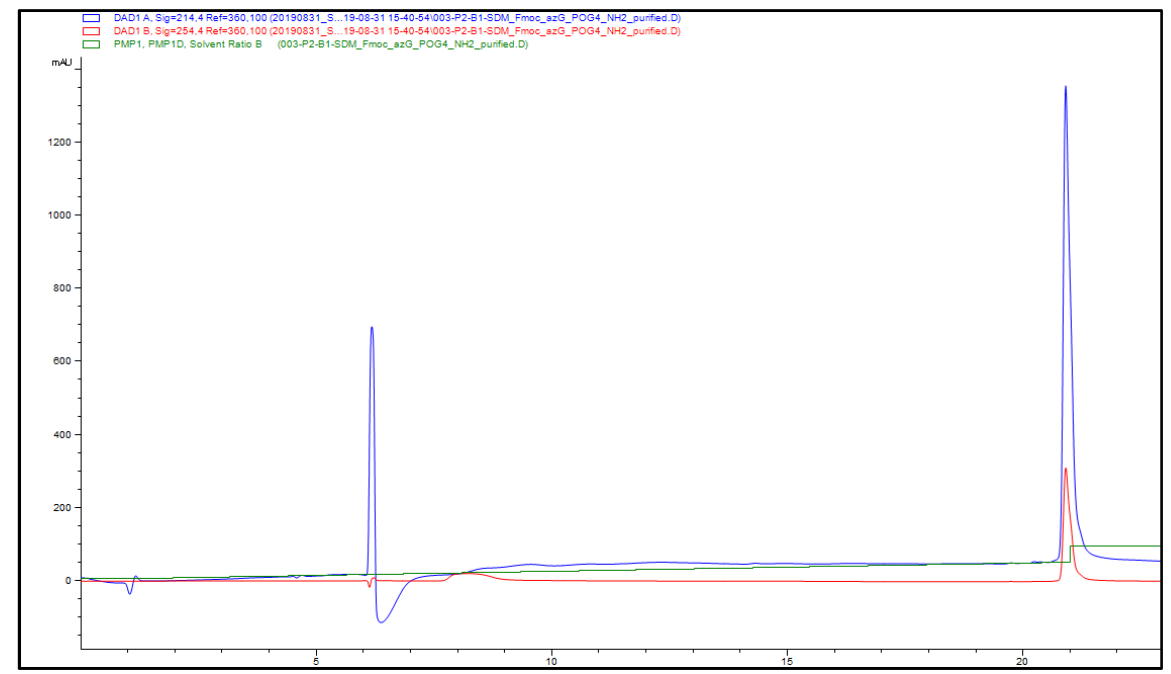


Compound 4: $\mathrm{H}-(\mathrm{azGPO})_{4}-\mathrm{NH}_{2}$

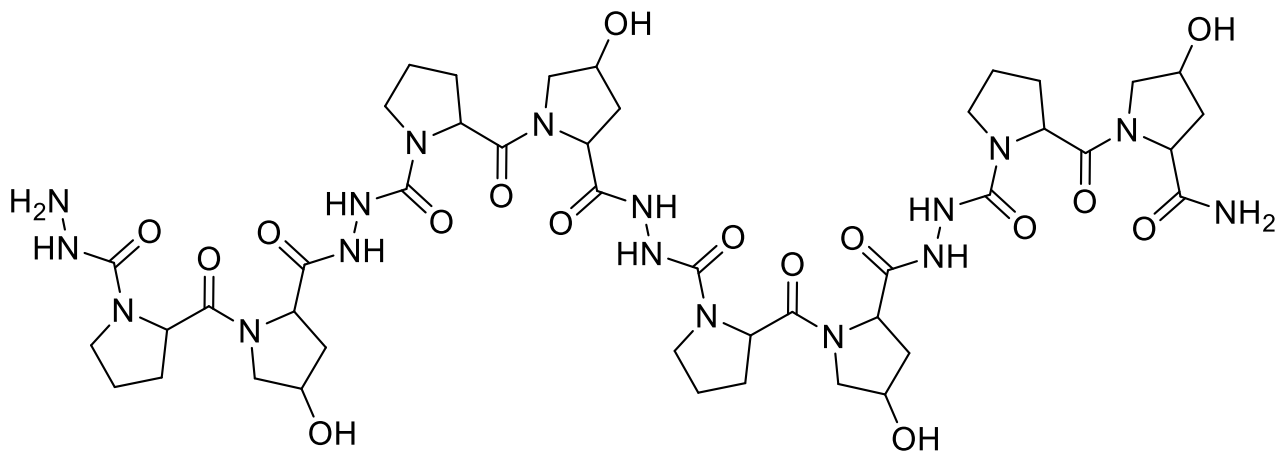

Purified HPLC Chromatogram: 1-25\% $\mathrm{CH}_{3} \mathrm{CN}$ in 0.1\% TFA $\mathrm{H}_{2} \mathrm{O}$ over 20 min

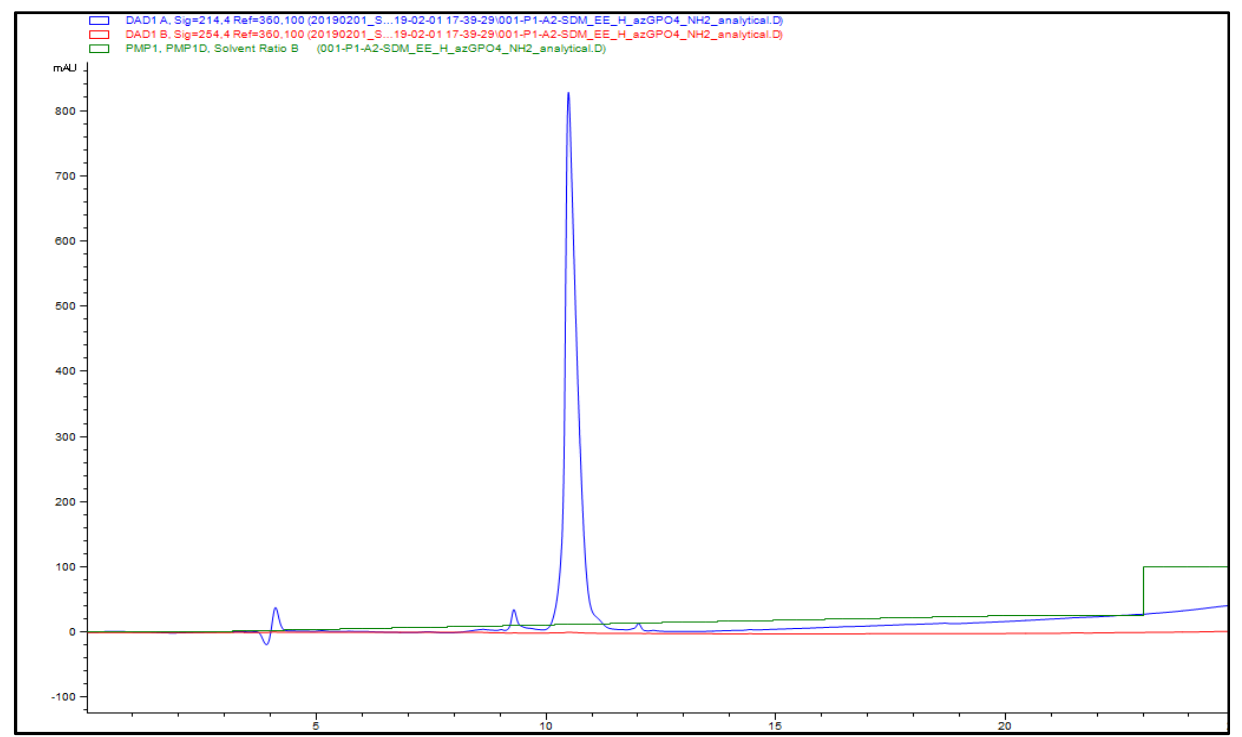




\section{Compound 5: $\mathrm{H}-(\mathrm{azGPO})_{5}-\mathrm{NH}_{2}$}<smiles>NNC(=O)N1CCCC1C(=O)N1CC(O)CC1C(=O)NNC(=O)N1CCCC1C(=O)N1CC(O)CC1C(=O)NNC(=O)N1CCCC1C(=O)N1CC(O)CC1C(=O)NNC(=O)N1CCCC1C(=O)N1CC(O)CC1C(=O)NNC(=O)N1CCCC1C(=O)N1CC(O)CC1C(N)=O</smiles>

Purified HPLC Chromatogram: 1-25\% $\mathrm{CH}_{3} \mathrm{CN}$ in 0.1\% TFA $\mathrm{H}_{2} \mathrm{O}$ over 20 min

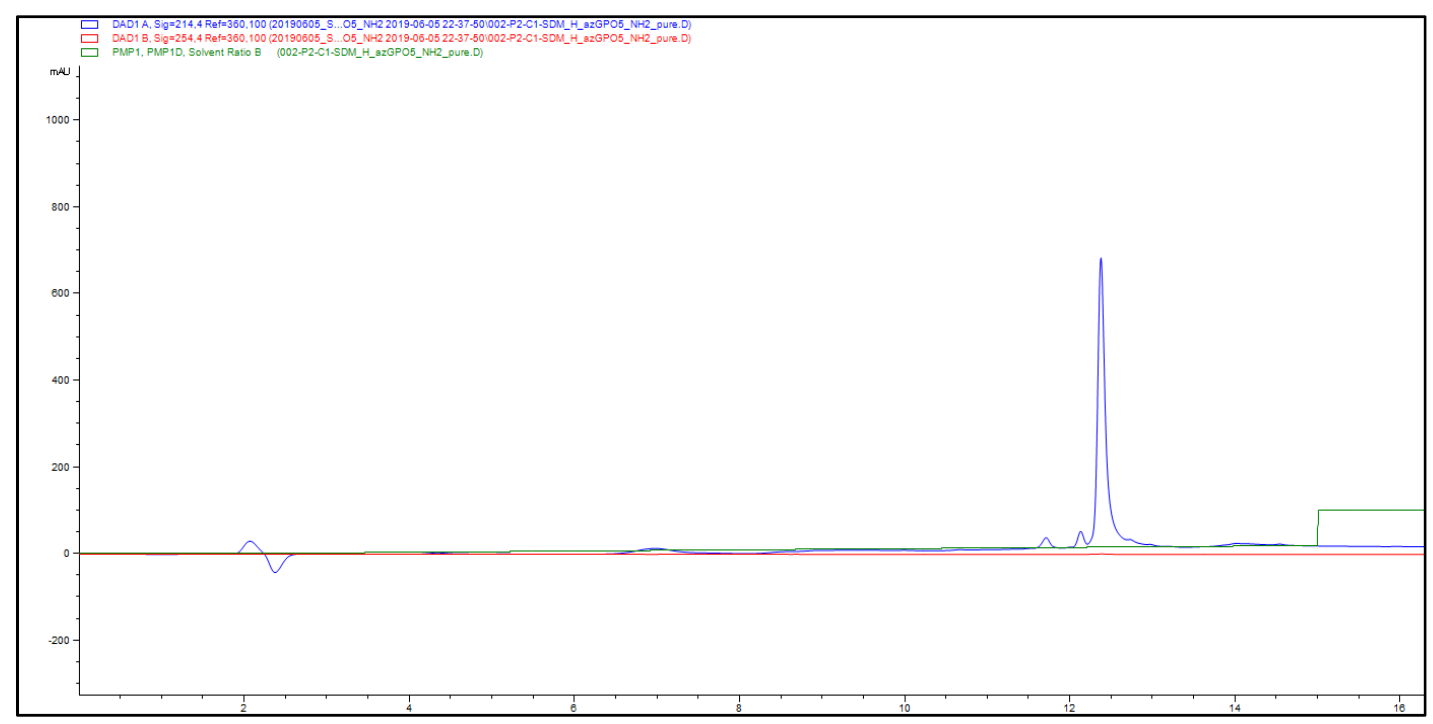




\section{Compound 6: Fmoc-(azG)-(V)-(POG) ${ }_{4}-\mathrm{NH}_{2}$}

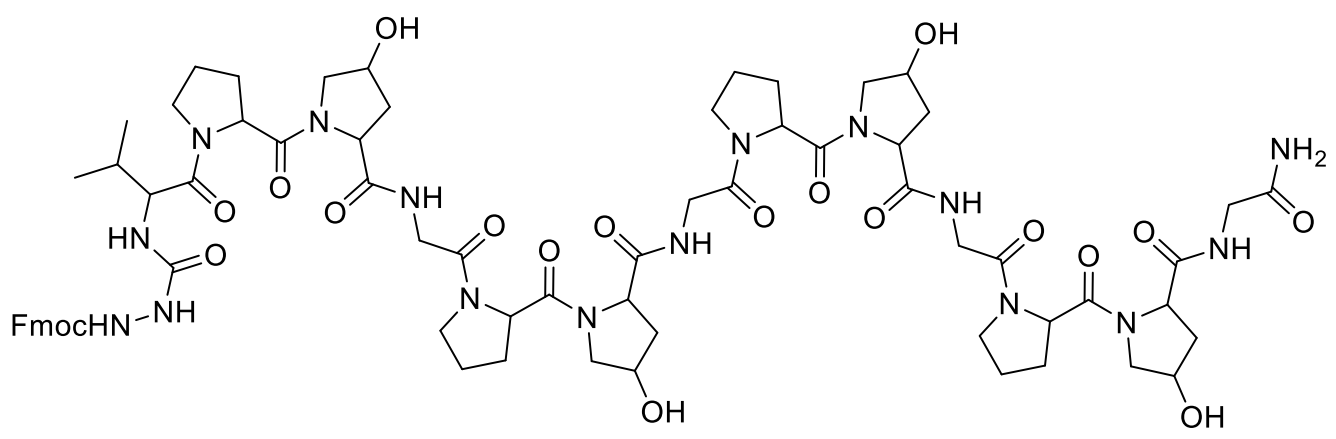

Pure HPLC Chromatogram: $5-40 \% \mathrm{CH}_{3} \mathrm{CN}$ in $0.1 \%$ TFA $\mathrm{H}_{2} \mathrm{O}$ over 30 min

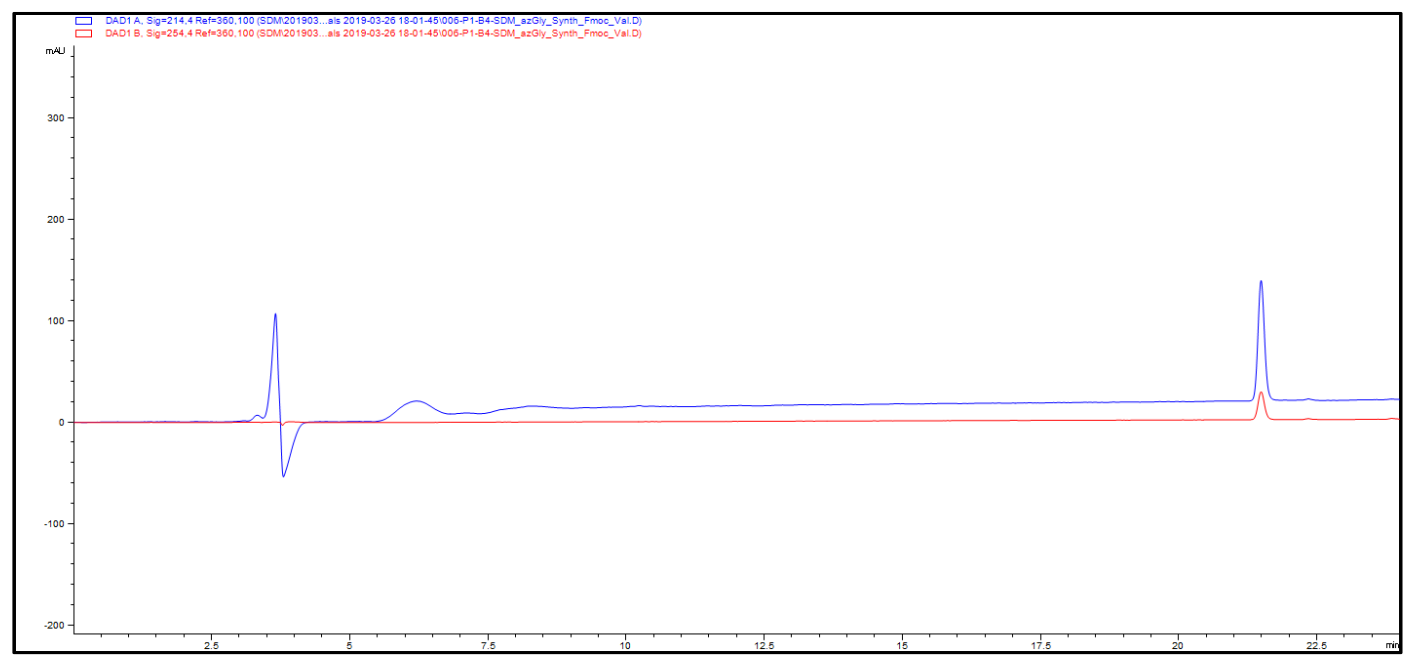




\section{Compound 7: Fmoc-(azG)-(N)-(POG) $)_{4}-\mathrm{NH}_{2}$}

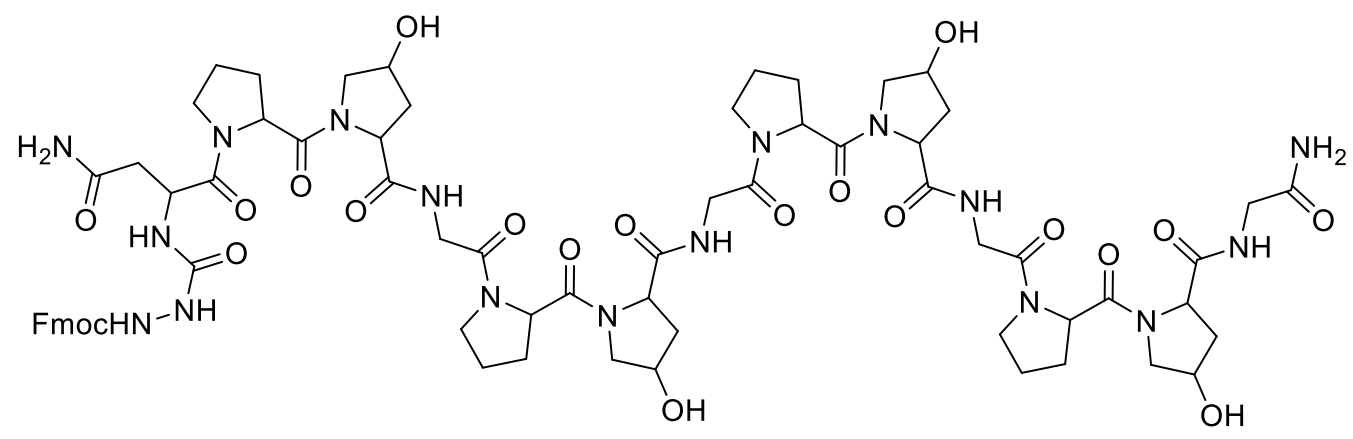

Pure HPLC Chromatogram: $5-40 \% \mathrm{CH}_{3} \mathrm{CN}$ in $0.1 \%$ TFA $\mathrm{H}_{2} \mathrm{O}$ over 30 min

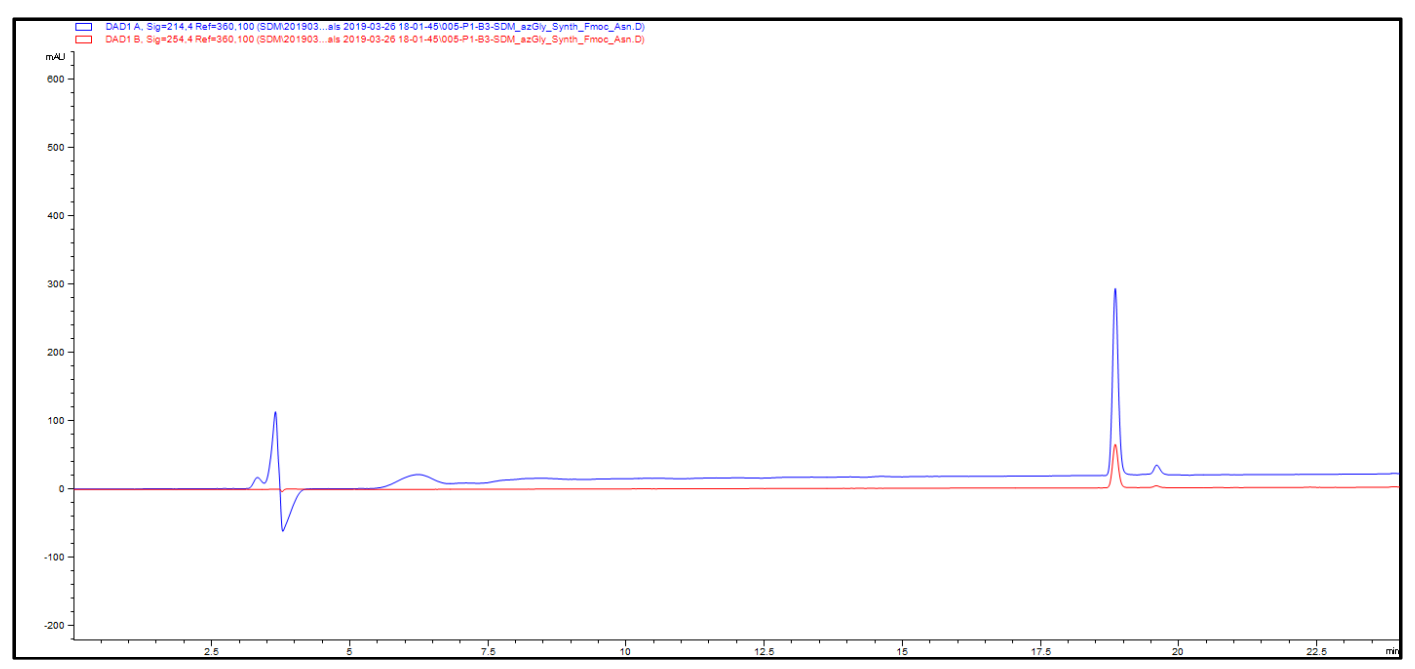


CIRCULAR DICHROSIM RESULTS
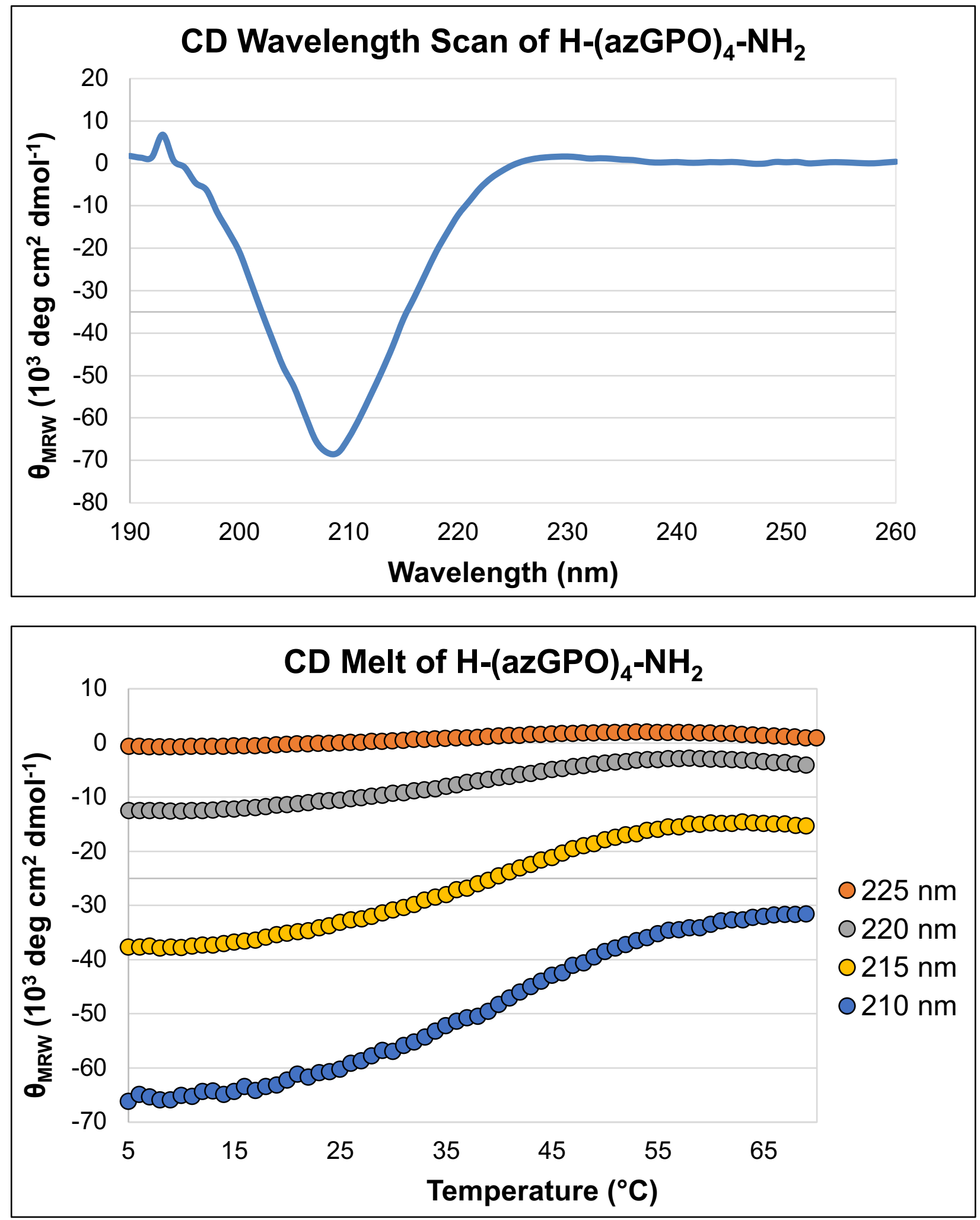

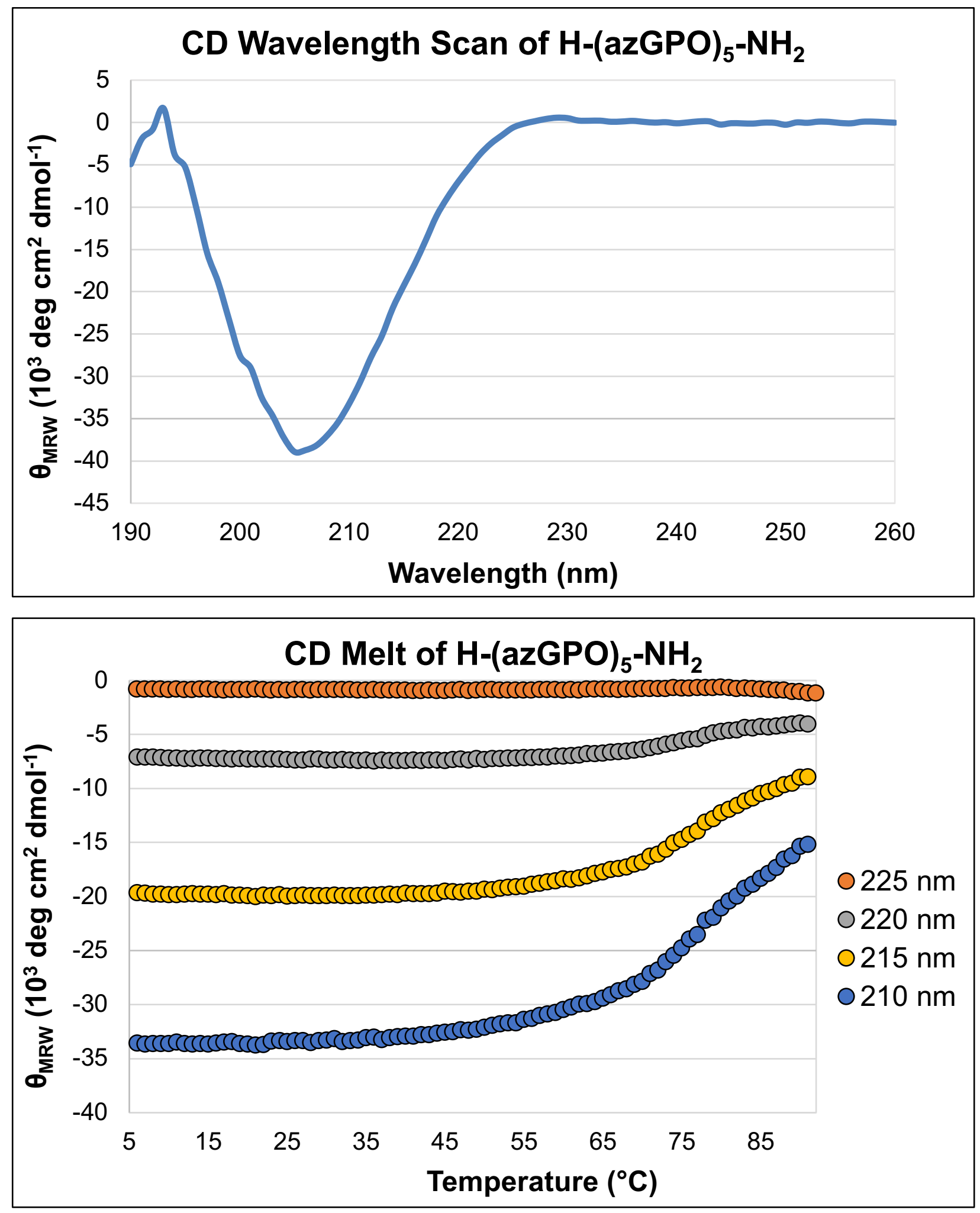